\title{
On Implementation of Low-cost Strategies for Domestic Hotels ${ }^{1}$ \\ Yuanchun Huang ${ }^{1}$ and Yongsheng Wang ${ }^{2}$
}

\author{
Keywords: Domestic hotels; Low cost; Strategic management; One-off products for hotels; \\ Environmental protection
}

\begin{abstract}
Domestic hotels have been greatly impacted with the entry of famous international hotels into China's market. On the basis of the characteristics in their development, domestic hotels are researched and their difficult situations are analyzed to propose some low-cost strategies for them in combination with some concepts in strategic cost management.
\end{abstract}

\section{Necessity for the Implementation of Low-cost Strategy in Domestic Hotels}

The concept of strategic cost management was first put forward by a British scholar in 1980s. "Cost advantage" was discussed by Michael E. Porter, an American scholar, in his books "Competitive Strategy" and "Competitive Advantage". On the basis of Porter's discussion, strategic cost management was made in detail by another American scholar in a professional book entitled "Strategic Cost Management" published in 1993. Thus, for recent years, it has been a powerful tool to strengthen cost management and to gain competitive advantage for enterprises in such advanced countries as Britain, USA and Japan.

It is important for the domestic hotels to implement low-coast strategies so as to raise their competitiveness and to lower their cost. The low-cost strategy is the one that is used by a hotel's manager to lower its cost in its business by means of a particular method to gain advantages in competitiveness. With China's entry into WTO, more and more international hotels begin to enter Chinese market with an increasing rate. In addition, large international groups, transnational corporations, hotel groups have moved part of their large sums of capital, advanced managerial skills and famous brand-names into the market of tourism hotels, making them fist flourish in luxurious hotels in the coastal cities, big or medium-sized, and then re-flourish in less luxurious hotels in inland cities, medium-sized or small. According to the statistics on mergers and acquisitions of hotels in recent years, it is found that the global hotel group superpowers tend to make plans to optimize the best global resources in hotels to conduct the global merging by crossing the countries, the regions and even the brand-names. In view of this, the superpowers will not be satisfied with the taking-over of a single hotel in China, and their aims are directing to the developing hotel groups and hotel management companies in China.

In many European and American countries, the tourism industry has been greatly emphasized, and its development has been favorably supported by the policies made by their governments. At the time when China opened its door to the outside world and began to build joint ventures in hotel industry, the famous international hotels have existed for decades and even for more than a hundred years, making them strong in capital, concepts, market coverage, high technology, brand-name popularity, service, etc. Furthermore, even at present, they are accelerating their speed in expansion and monopoly by popularizing their brand-names to Chinese market and the markets in other parts of the world and by increasing their investment in their training in hotel education and culture. Since the beginning of the 21 st century, the Marriott International began to enter China with large amounts of capital on a high basis, and since then many other international hotels have started to share Chinese market of hotel, including Hyatt Hotels Corporation, Accor, Sheraton, JAL Hotels Company Ltd, Hilton Worldwide Holdings Inc., Kempinski Hotels, etc. Those hotels are a great challenge to Chinese hotel industry: international competition in China, and internationalization of Chinese market.

Through years' development, domestic hotels have formed their own characteristics in scale, integrity of grouping hotels, network development, and humanistic management of human resources and the individual growth of their staff. The input of civilian capital makes them more 
energetic in business, while the low-cost strategy may raise their profit to a certain degree, so that the content of cost management for modern hotels is enriched and the ability of domestic hotels to manage cost is improved. To improve their management performance and to guarantee their managerial competitiveness against international hotels, domestic hotels should in detail analyze and completely manage their own logistics, capital flow, information system, and value by means of analytical tools of strategic cost management concerning value chain, cost motive and strategic positioning.

\section{Establishment of Low-cost Culture for Enterprises}

To Cultivate Staff's Economical Consciousness by Training and Stimulation. In the daily managerial work of hotels, it is significant for the staff to be of economical consciousness, and their consciousness on cost should be enhanced by giving their staff the favorable language and material stimulation. As managers of some departments, they should make weekly cost training plans for their staff, who will get to know what cost is, how to control it, and how important it is to control it by taking part in the training. Meanwhile, the managers should work together with their staff to determine standard cost by using scientific methods, and set it as an aim for the staff, who will pay more attention to it and work hard to realize it. In hotels, cost control is a long-term task, and the cost should be lowered by all means. For example, some files, notice and regulations for its own use of the hotel can be printed on the other side of the used paper, the other side of some paper for financial statements can be used for paper of rough draft, soaps and detergent left over by the guests can be collected and placed in staff's washrooms, broken table cloth can be recycled as a rag, room lighting system should be adjusted according to the change of seasons, lights and air-conditioners should be turned off upon staff's departure, the surplus parts should be made full use of after the food is processed, and so on so forth. Only by doing so, can hotel staff be more conscious of cost control and management, so that they will form the economical consciousness.

To Let Every Employee Participate in Management. Every employee in the hotel should be clear that cost control depends on every one in it, regardless of leaders or employees, for hotel activities are conducted by human beings, each of whom plays a crucial role in every functional stage of cost. Consciousness on cost concerns its controlling and saving, which is closely related to an enterprise's life and death, and thus every employee should be of this consciousness to participate in cost management, which is not only the responsibility of a certain departments or certain leaders, but a thing that matters to everyone, including all the employees. Only by setting up the employee's cost consciousness, can all the measures and policies to lower cost be implemented in an active and smooth way.

To Fix on A Cost Budget and A Reward and Punishment System Based on Cost Evaluation. A quantitative way to control cost is to design a cost budget, which aims at a detailed description for every cost. The actual cost will be evaluated according to the designed cost budget, which guarantees the realization of cost control, and which should be made out in a complete, individualized, reasonable and challenging way. Some hotels tend to make evaluation rules for the front-desk departments and somewhat ignore the back-desk ones, which is not appropriate. Some hotels make an evaluation on the total cost without excluding some uncontrollable cost, such as the commission for payment using credit cards and business tax, which is not fair to some individuals. In addition, the uncontrollable cost will make the evaluation result become unfair to the some individual employees, who will lose power to go on. Thus, the cost budget should be controllably and reasonably designed in accordance with the features of every department, and meanwhile it should be challenging so that every member will make effort to actualize it. If it is too hard on them, the employees will fail to finish it, and if it is easy to complete, then it is of no use controlling it. The standard for the budget should be decided on according to the previous data, characteristics of each department, and future trend of the hotel and its strategies. The standard should be issued monthly by making adjustments to the unreasonable parts, whose causes should be analyzed so that mistakes will be corrected to make the cost more controllable later on. The evaluation can be made annually or every half year by rewarding those who do well and punishing those who fail to reach 
the standard. It can also be made annually or every half year in combination with the good performance award, and in this way, it also serves as an important evaluation standard for the good performance award. When evaluated, the unreasonable cost budget standard should be analyzed for its problems that should be put right in the future budget. In evaluation, the variable cost can be measured in rates. For example, cost rate for food and dishes may be used to evaluate the staff working in the kitchen; cost rate for food and drinks, to evaluate those working in the bar; the rate of consumption of cleaning products, porcelain and glass utensils to the income of food and drinks, to evaluate whose in stewarding department; the cost rate of consumption of room cleaning products, items used by guests and office supplies to the room revenue, to evaluate those in the guest house department; fees for office supplies and telephone calls, to evaluate those in back-desk departments; fees for repairs and maintenance, to evaluate those in the engineering department; and the staff whose work concerns fixed fees such as telephone tolls can be evaluated in terms of absolute numbers.

To Establish "Human-centered" Concept in Cost Control. Human plays a fundamental role in management and business dealings. Cost control and its implementation rely on the whole working staff of a hotel instead of the financial staff. As a result, to get the maximal and optimal participation and enthusiasm of all the staff, it is crucial to establish the "human-centered" managerial concept in cost control so as to make full use of human's value, potential, energy and moral quality, for the staff know better of the hotel's business procedure, service regulations and the expenditure of consumable products in daily dealings, so that they are able to control cost anytime and anywhere in almost every occasion. Thus, the effect of cost control is significantly improved due to the full play of staff's potential and consciousness on cost control.

\section{Introduction of Strategic Cost and Upgrade of Hotel's Concept of Cost Management}

Based on the theories in strategic management, strategic cost management, whose main analytical approaches are borrowed from battle managerial system, is newly born from the functional extension of traditional cost managerial system. From the perspective of strategy, its main framework of analysis is a reasonable combination of the analytical approaches of strategic management and the emergence and application of cost information. In battle management, there are three analytical approaches closely related to cost factors: analysis of value chain, that of strategic positioning and that of cost motive.

Determination of One's Own Value Chain through Horizontal and Vertical Choice of the Target Market. As an analytical tool, analysis of value chain, as seen from the perspective of strategic cost management, may produce an enterprise's developmental strategies that will exert great influences on its cost managerial modes, due to the symbiosis between the emergence of an enterprise's cost and its value, and due to the fact that all cost can be distributed to the emergence of a certain value. Analysis of value chain includes the internal analysis of an enterprise, the analysis of value chain of its competitors, and the analysis of value chain in the same business. By an internal analysis of an enterprise, we can see the whole process of consumption from the purchase of hotel's materials to their sale to the guests, and we can also see the value chain with a series of joints, each of which is indispensable to an enterprise's cost control. By an analysis of value chain of a hotel's competitors, the connection of its value chain will be made more reasonable by finding out the problems in each joint and their causes. By an analysis of value chain in the same business, the cost of a hotel will be lowered by a vertical integrity of all the suppliers or by a confederation with them by signing contracts.

Determination of the Orientation of A Hotel's Strategic Cost Management. The orientation should be determined

According to the competitors: The competitor is actually a replacement of the hotel's products. By doing an investigation of the accurate information of its competitors' products, a hotel can keep the information on file and then makes a comparison of the general competitive situation in the target market with its current advantages and disadvantages so as to make a final decision. 
According to the use of the products: The basis of this kind of orientation is to locate the use of each product and to analyze the market situation for this kind of use. The same hall, for example, may be used as a venue for a large-scale banquet or a cafeteria, as a meeting hall for conferences, and also as a location for all kinds of exhibitions. For such a product in hotel as the hall, the hotel can accommodate it to different target markets and use it for different products.

According to the users: As a common way of orienting its products, the user-oriented method is to applied to direct certain products to the appropriate users or to locate them to a certain target market, so that the proper image of the product can be created by the users or the target market. A case in point is the operation of some hotel's less luxurious restaurants, which are opened according to the local people's preference for "convenience, economy and rich flavors".

According to the level of products: This means of orientation aims to put a certain product to the level of another similar product so as to create a kind of contrastive effect. For example, some hotels regard their own guest rooms as being equal to the level of guest rooms in a well-recognized hotel so that the guests are willing to buy their products; viewed from another point of view, such kind of orientation aims to seek a reference for certain kind of product, and to make it stand out of the similar level of products. Another example is that some hotels promote their apartment rooms to the users, boasting that their kitchen facilities are more applicable to the traveling family members as compared to the similar level of standard rooms, so that more users will be attracted to buy their products.

Implementation of Strategic Cost Management According to Analysis of Cost Motive on Basis of Analysis of Value Chain and Analysis of Strategic Positioning. It is necessary to apply the analysis of cost motive to strengthen a hotel's daily cost management. Modern hotel's cost management is a managerial process of the whole hotel in all its aspects, and it is a mix of its flow of materials and that of services, and also a mix of managerial technology and information technology. In modern hotel's cost management, the strategic management plays a significant role in breaking through the limitations of traditional cost management, and in transferring the focus to the whole strategy of the hotel. By means of analyzing the cost of internal flow of materials, external mode of purchase, service orientation, financial operations, the competitors and the market situation, strategic management will help a hotel to forecast its cost and to make decisions so as to select an appropriate business strategy for it, to deal well with the relationship between its development and its enhanced cost management, and to raise its general economic profit.

\section{Acknowledgement}

This paper serves as one of the research results for "2015 Liaoning Provincial Fund Project for Social Science"(Registration No.: L15BJY010) and "2015 Liaoning Provincial Planned Program for Educational Science"(Registration No.: JG15DB035).

\section{References}

[1] ZOU Yi-min, "Hotel Management: Its Theory, Approaches and Techniques" (The first version, published in April, 2010), Higher Education Press

[2] ZHOU Yang, "On International Business of Tourism Industry in China" (Published in April, 2013), Economic Management Press

[3] "Reports on Development of Hotels in China (From 2012 to 2013)", Tourism Research Institute of China and Tourism Education Press

[4] Barsamian A, Hammar M. Connecting the resources: Authenticity, mass customization\& revenue [R]. Foodservice Institute of America (FIA) White paper based on the symposium held at Rush University Medical Center, Chicago, Illinois, 2008

[5] He Jianmin. On competitive strategy option models for China's local and transnational tourist hotel groups and their specific choices [J]. Tourism Science, 2004, 18(4): 18-21 
[6] Zeng Guojun, LiQing. Expansion strategies of hotel groups: An investigation of hotel groups in china [J]. Tourism Science, 2008, 22(2):56-62.

[7] Reisinger Y, Steiner C J. Reconceptualizing objiect authenticity [J]. Annals of Tourism Research, 2006, 33(1)65-86.

[8] Jamal T, Hill S. Developing a framework for indicators of authenticity: the place and space of cultural and heritage tourism [J]. Asia Pacific Journal of Tourism Research, 2004, 9(4):353-371

[9] ISO/IEC Guide 76. Development of standards for services-recommendations for addressing consumer issues [S].Geneva: International Organization for Standardization/International Electrotechnical Commission, 2006.

[10]Zhu Dingming. Research on core competence of the Chinese fast food corporation [D]. Chengdu: Sichuan University, 2007.29.

Miss Huang Yuanchun is professor of Bohai University College of Tourism, and she also acts as supervisor of postgraduate students.

As the corresponding author of this paper, Mr. Wang Yongsheng is an associate professor of Bohai University College of Foreign Languages. 